\title{
A rare congenital abnormality leading to chronic kidney disease in an adult male
}

\author{
Appuhamy $\mathbf{S}^{1}$, Yu $\mathbf{R}^{1}$, Kennedy $\mathbf{D}^{1}$ \\ Journal of the Ceylon College of Physicians, 2021, 52, 53-55
}

\begin{abstract}
Prune Belly Syndrome (PBS) is a rare congenital disorder almost exclusively affecting males with most patients not surviving beyond infancy. We present a middle-aged man who received a diagnosis of PBS during investigation of newly diagnosed chronic kidney disease and his management.
\end{abstract}

A 35-year-old asymptomatic man who was referred by his general practitioner for further evaluation of incidentally detected end-stage chronic kidney disease. A non-contrast CT scan of the urinary tract revealed absence of anterior abdominal wall musculature, abnormal kidneys, bilateral hydroureter, and a thickened enlarged bladder. A prompt diagnosis of PBS was made with the CT findings in the clinical context of protruding abdomen and bilateral absent testes. He was managed with bladder decompression with an indwelling urinary catheter and a urology referral was made for consideration of reconstruction of ureters and renal transplant.

This case emphasizes the possible first encounters with this rare congenital condition even in adults, and thus the need to improve awareness among clinicians about its prompt diagnosis and appropriate treatment for better clinical outcomes.

Key words: prune-belly syndrome, cryptorchidism, urinary tract dilation, abdominal wall laxity, abdominoplasty

${ }^{1}$ Royal Hobart Hospital, Australia.

Correspondence: SA, e-mail: shenal.appuhamy@gmail.com

iD https://orcid.org/0000-0002-9615-5394

\section{Introduction}

PBS is a rare congenital disorder with an incidence of 3.8/100,000 live births. ${ }^{1}$ The condition affects males in $96 \%$ of the cases. It was first described by Fröliche in 1839 and given the name PBS in 1931 by Eagle and Barrett. ${ }^{2}$ It is also known as Eagle-Barret Syndrome, Obrinsky syndrome and the triad syndrome. There is no consensus among experts regarding the pathogenesis and mainly two theories exist. One is a lateral plate mesodermal developmental arrest between 6-10 weeks ${ }^{3}$ and the other is a utero bladder outflow obstruction. ${ }^{4}$ The genetic basis is again not clearly understood, but the role of several genetic mutations including HNF-1B has been proposed. ${ }^{5}$ The case reports describing the condition among twins ${ }^{6}$ including cases in monozygotic twins, ${ }^{7}$ a familial predisposition and association with other chromosomal abnormalities such as 13,18 and $21^{8,9}$ suggest a genetic basis for the disorder.

The classic syndrome is characterized by a triad of deficiency of abdominal wall musculature, cryptorchidism, and renal tract abnormalities. There is a wide spectrum of clinical severity and Woodard classified patients into three groups: Category 1 includes patients with pulmonary hypoplasia and oligohydroamnios in addition to renal dysplasia; Category 2 with full triad of the syndrome with moderate or unilateral renal dysplasia and no pulmonary hypoplasia; Category 3 with incomplete or mild triad features with no renal dysplasia or pulmonary hypoplasia. ${ }^{10} \mathrm{~A}$ variety of other associated congenital malformations including musculoskeletal, gastrointestinal, cardiopulmonary malformations have also been described in literature. ${ }^{11}$

Received 13 April 2021, accepted 18 Mayl 2021.

This is an open-access article distributed under the terms of the Creative Commons Attribution License, which permits unrestricted use, distribution, and reproduction in any medium, provided the original author and source are credited. 
Although there are many case reports and series reported from a single institution, majority of them describe diagnosis and management in-utero or in childhood. There are few case reports on diagnosis in adult life but optimal management of such patients is unclear. ${ }^{12,13,14}$

\section{Case report}

A 35-year-old man was referred by his general practitioner when he was noted to have a serum creatinine of $900 \mu \mathrm{mol} / \mathrm{L}$ on routine blood tests done for migration visa purposes. He did not have any health complaints. On direct questioning he came up with non-specific symptoms of malaise, fatiguability and exertional shortness of breath. He denied a history of hematuria or frothy urine. He also denied symptoms suggestive of recurrent urinary tract infections. There was no history of symptoms suggestive of bladder outflow obstruction. The patient migrated to Australia from India 5 years ago to pursue higher studies to become a catholic priest and is unmarried.

On examination, he was an overweight man with a BMI of $27.3 \mathrm{~kg} / \mathrm{m}^{2}$ without any dysmorphic features and well developed secondary sexual characteristics. He had a mild kyphosis and mild pallor without jaundice. His mucous membranes were dry, skin turgor was decreased, and capillary refill was 2 seconds suggesting mild dehydration. Cardiovascular examination revealed blood pressure of $195 / 90 \mathrm{mmHg}$ in both arms and heart sounds were dual without murmurs or a pericardial rub. Respiratory and neurological examinations were normal.
Abdominal examination revealed a distended abdomen resembling a 'pot belly'. Abdominal wall was lax and a ballotable mass was felt in the left flank, suggesting an enlarged left kidney. Non-tender urinary bladder was palpable at the level of the umbilicus. Bilateral testes were absent, but the penile examination was normal.

Investigations revealed a serum creatinine level of $946 \mu \mathrm{mol} / \mathrm{L}$ with an estimated glomerular filtration (eGFR) rate of $6 \mathrm{ml} / \mathrm{min}$. Serum electrolytes were within normal range, but serum phosphate was high at 2.03 $\mu \mathrm{mol} / \mathrm{L}$. There was evidence of a normocytic, normochromic anemia with a hemoglobin of $10.2 \mathrm{~g} / \mathrm{dL}$. Iron studies revealed evidence of iron deficiency with a low serum ferritin of $36 \mathrm{microg} / \mathrm{L}$ and transferrin saturation of $17 \%$. Urine microscopy showed 4 pus cells and 2 red cells per high power field and did not grow organisms on culture. Urine protein/ creatinine ratio was $5.1 \mathrm{mg} / \mathrm{mmol}$.

A non-contrast CT scan organized to assess for obstructive urinary pathology showed a markedly atrophic right kidney, and the left kidney was multilobulated with moderate to severe hydronephrosis. There was evidence of severe bilateral hydroureter with tortuous ureters (Figure 2). Urinary bladder was distended with a thickened wall. Anterior abdominal wall musculature was absent (Figure1). There was a soft tissue structure measuring $43 \times 26 \times 41 \mathrm{~mm}$ identified posterior to the bladder, which was thought to be developmental (Figure 3).

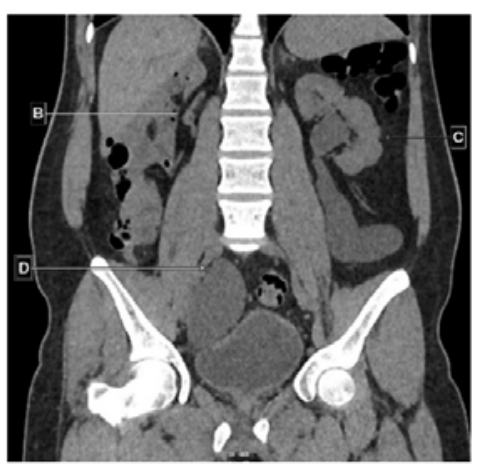

Figure 1.

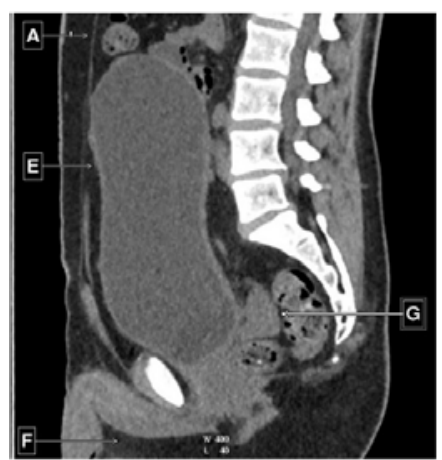

Figure 2.

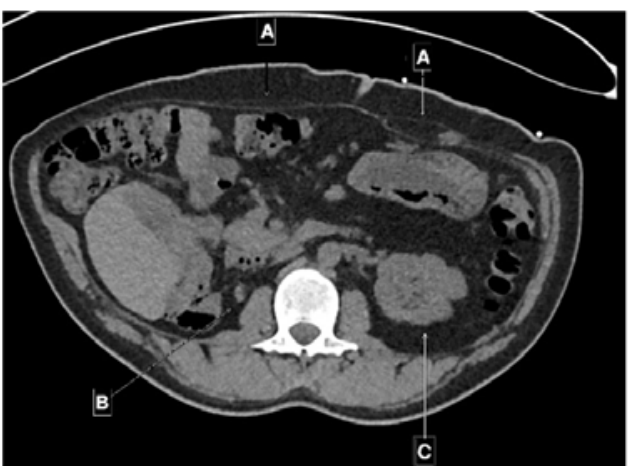

Figure 3.

NON-CONTRAST CT ABDOMEN FINDINGS Figure 1. (Axial plane) demonstrates near complete absence of the anterior abdominal wall musculature [A], an atrophic right kidney [B] and a macro-lobulated dysplastic left kidney [C]. Figure 2. (Coronal plane) demonstrates right megaureter/hydronephrosis [D]. Figure 3. (Sagittal plane) demonstrates a grossly distended, mildly thick-walled urinary bladder [E], absent testes within the scrotal sac $[F]$ and mass like dysplastic seminal vesicles sitting on the posterior wall of the bladder [G]. 
He was initially hydrated with intravenous fluids and then encouraged to increase his oral intake. Initial bedside bladder scan revealed $3 \mathrm{~L}$ of residual urine, so an indwelling urinary catheter was inserted which was left in-situ. Elevated blood pressure was controlled with antihypertensives. Oral iron supplements and oral phosphate binders were prescribed. He was discharged with a plan to be followed up in the outpatient nephrology clinic. A referral was made to the outpatient urology clinic for possible surgical intervention of the urinary tract anatomical abnormalities.

During the follow up at urology clinic, it was planned to perform ureteral and bladder reconstruction surgery at the same time with a renal transplantation. While awaiting a donor organ, patient is currently undergoing intermittent hemodialysis and is regularly followed up at the nephrology outpatient clinic. The patient remains well with marked improvement in fatigue and malaise.

\section{Discussion}

Although there are many case reports about the diagnosis and management of PBS in-utero up to early childhood, there are only few cases describing newly diagnosed adult patients with PBS and chronic renal failure. ${ }^{14}$

Our patient had the classic triad of phenotypic features of PBS. His presentation is compatible with mild form of the condition (Woodard classificationcategory 11) with late onset renal impairment.

The ability for a clinical suspicion of PBS to be confirmed by a CT scan should be emphasized. This is reported in previous literature. 15 In our opinion, the management should be targeted at preventing further insults to the already compromised urinary tract, management of complications of chronic kidney disease and prompt initiation of renal replacement therapy together with urinary tract reconstruction surgery.

\section{Conclusion}

This case report highlights the need for clinicians to be aware of PBS as a possible etiology of developmental abnormalities in the urinary tract even in adults. This allows prompt diagnosis and proper management leading to good clinical outcomes.

\section{References}

1. Routh JC, Huang L, Retik AB, Nelson CP. Contemporary epidemiology and characterization of newborn males with prune belly syndrome. Urology 2010; 76(1): 44-8.

2. Eagle JF Jr; Barrett GS. Congenital deficiency of abdominal musculature with associated genitourinary abnormalities: A syndrome. Report of 9 cases. Paediatrics 1950; 6(5): 72136. PMID: 14797335.

3. Ives EJ. The abdominal muscle deficiency triad syndrome: experience with ten cases. Birth Defects Orig Artic Ser. 1974; 10(4): 127-35. PMID: 4283493.

4. Moerman P, Fryns J-P, Goddeeris P, Lauweryns JM. Pathogenesis of the Prune-Belly Syndrome: A Functional Urethral Obstruction Caused by Prostatic Hypoplasia. Pediatrics 1984; 73(4).

5. Granberg CF, Harrison SM, Dajusta D, et al. Genetic basis of prune belly syndrome: Screening for HNF $\beta$-gene. J Urol 2012; 187(1): 272-8. DOI: 10.1016/j.juro.2011.09.036.

6. Audu L, Mairami A, Mukhtar-Yola M, et al. Prune belly syndrome in a set of twins, a family tragedy: Case report. Niger J Paediatr. 2013; 40(4): 428.

7. Balaji KC, Patil A, Townes PL, Primack W, Skare J, Hopkins T. Concordant prune belly syndrome in monozygotic twins. Urology. 2000; 55(6): 949. doi: 10.1016/s0090-4295(00) 00452-0. PMID: 10840120.

8. Frydman M, Magenis RE, Mohandas TK, Kaback MM. Chromosome abnormalities in infants with prune belly anomaly: Association with trisomy 18. Am J Med Genet. 1983; 15(1): 145-8.

9. Amacker EA, Grass FS, Hickey DE, Hisley JC, Opitz JM, Reynolds JF. An association of prune belly anomaly with trisomy 21. Am J Med Genet. 1986; https://doi.org/10.1002/ ajmg.1320230406

10. Woodard JR. The prune belly syndrome. Urol Clin North Am. 1978; 5: 75-93.

11. Grimsby GM, Harrison SM, Granberg CF, Bernstein IH, Baker LA. Impact and frequency of extra-genitourinary manifestations of prune belly syndrome. J Pediatr Urol. 2015; 11(5): 280.e1-280.e2806. doi:10.1016/j.jpurol.2015.06.005

12. Fabris A, Pellanda MV, Gardin C, Contestabile A, De Vivo E. Prune-Belly Syndrome in a Geriatric Patient. Nephron. 2000; 86: 251-2. doi.org/10.1159/000045775

13. Asplund J, Laska J. Prune belly syndrome at the age of 37 . Scand J Urol Nephrol 1975; 9(3): 297-300. doi: 10.3109/ 00365597509134231. PMID: 128814.

14. Lee SM. Prune-Belly Syndrome in a 54-Year-Old Man. JAMA J Am Med Assoc 1977; 237(20): 2216-7.

15. Wen C, Marques D. Article - Eagle Barrett Syndrome (also known as prune-belly syndrome [PBS]) in an adult. Appl Radiol. [cited 2020 Sep 16]. Available from: https:// appliedradiology.com/articles/eagle-barrett-syndrome-alsoknown-as-prune-belly-syndrome-pbs-in-an-adult 